\title{
Recent advances in funtional neuroimaging techniques
}

The article "A review of new minimally invasive brain stimulation techniques in psychiatry", published in this periodical, ${ }^{1}$ provides an excellent overview of transcranial magnetic stimulation technique (TMS), among other new methods. The TMS technique has become an important non-pharmacological tool for the treatment of psychiatric disorders.

The authors emphasized that there is still a need to better define ideal parameters to be used to optimize the therapeutic effects of the technique, such as the percentage of motor threshold and frequency of stimulation, duration of each application, interval between sessions, and etc. ${ }^{2}$

I would like to comment on an additional aspect that requires further evaluation: the number of days of TMS treatment, which was not discussed in Jho et al's article.

In almost all TMS trials reported to date, treatment duration

\section{References}

1. Chae JHO, Li X, Nahas Z, Kozel FA, George MSA. Review of the new minimally invasive brain stimulation techniques in psychiatry. Rev Bras Psiquiatr 2001;23:100-9.

2. Figiel GS, Epstein C, McDonald WM, Amazon-Leece J, Figiel L, Saldivia A, et al. The use of rapid rate Transcranial Magnetic Stimulation (rTMS) in refractory depressed patients. J Neuropsychiatry Clin Neurosci 1998;10:20-5.

3. Pascual-Leone A, Rubio B, Pallardo F, Catala MD. Rapid-rate transcranial magnetic stimulation of left dorsolateral prefrontal cortex in drug-resistant depression. Lancet 1996;348:233-7. ranged from one to two weeks ${ }^{3,4}$ (corresponding to approximately 5 to 10 applications). An interesting study conducted by Pridmore et al in Australia ${ }^{5}$ reported a blind comparison between electroconvulsive therapy and TMS for major depressed patients without limiting the number of days for each treatment. A group of 32 patients were randomly divided to receive either high frequency TMS or unilateral ECT. In both subgroups, the applications were continued until clinical improvement occurred. Patients who received TMS needed a mean of $13.1+3.1$ sessions to achieve clinical remission. Based on these data, one can raise the hypothesis that, similarly to ECT, TMS requires extended periods of treatment to be clinically effective, possibly 3 weeks on average.

Moacyr Alexandro Rosa

Instituto de Psiquiatria do HC-FMUSP, São Paulo, Brasil

4. Berman RM, Narasimhan M, Sanacora G, Miano AP, Hoffman RE, $\mathrm{Hu} \mathrm{XS}$, et al. A randomized clinical trial of repetitive transcranial magnetic stimulation in the treatment of major depression. Biol Psychiatry 2000;47:332-7.

5. Pridmore S, Bruno R, Turnier-Shea Y, Reid P, Rybak M. Comparison of unlimited numbers of rapid transcranial magnetic stimulation (rTMS) and ECT treatment sessions in major depressive episode. Int J Neuropsychopharmacol 2000;3:129-34. 